\title{
The Treatment of Effluent from Food Industry Using Anaerobic-Aerobic Process with MBR system
}

\author{
AL-Saadi Anmar Joudah, Gabriel Racoviteanu
}

\begin{abstract}
Wastewater treatment of the food industry by using a combination of the anaerobic-aerobic process as a pre-treatment and the bioreactor treatment represented by MBR system has been proven as an efficient single step process to treat industrial wastewater and produced an excellent effluents quality suitable for reuse. In this study, three phases of anaerobic biodegradation were used as the first step of biological pre-treatment, with the time of fermentation 5,10 and 15 days respectively. At each phase, the aerobic biodegradation process was performed to activate sludge at periods of $2,4,8$, and 24 hours, respectively, with the MBR system using hollow fibre membrane type $\mathrm{ZW}-10$ that's operating under a low-vacuum. $\mathrm{NaOCl}$ solution has been adding in the bioreactor tank during the backwashing process. Twenty-eight of samples were collected from the influents and the effluents during the biological and bioreactor treatments. The samples were tested for eight water quality tests: temperature, Dissolved Oxygen (DO), pH, Turbidity, Total Suspended Solids (TSS), Mixed Liquor Suspended Solids (MLSS), Chemical Oxygen Demand (COD), and Biochemical Oxygen Demand (BOD5). The results indicated that the bioreactor system can be used efficiently to treat the effluent of food industry from meat processing. The results of the first phase PI (after 5 days of fermentation) considered as the best phase, which provided the excellent removal efficiency of TSS, BOD $_{5}$, and COD to reached $98.31 \%, 94.53 \%$, and $95.56 \%$ respectively at HRT $24 \mathrm{~h}$.
\end{abstract}

Index Terms - Effluent from meat processing, anaerobic-aerobic treatment, ZW-10 membrane

\section{INTRODUCTION}

Aerobic treatment systems such as the conventional activated sludge process are one of process widely adopted for treating low strength wastewater $(<1000 \mathrm{mg} \mathrm{COD} / \mathrm{L})$ like municipal wastewater. Conventional activated sludge process is energy intensive due to the high aeration requirement and it also produced a large quantity of sludge (about $0.4 \mathrm{~g}$ dry weight/g COD removed) that has to be treated and disposed of. Anaerobic process for wastewater treatment is an alternative, which is potentially more cost-effective, particularly in the subtropical and tropical regions where the climate is warm consistently throughout the year. Anaerobic wastewater purification processes have been increasingly used in the last few decades. These processes are important because they have positive effects: removal of higher organic loading, low sludge production, high pathogen removal, methane gas production and low energy consumption, [1]. In

Al-Saadi Anmar Joudah, Dept. of Water Engineering, Technical University of Civil Engineering of Bucharest/ Faculty of Hydrotechnics/ Bucharest/ Sector 2, 124 Lacul Tei Bvd., www.utcb.ro, Romania, Mobile No. +40730484224

Professor Gabriel Racoviteanu, Dept. of Water Engineering, Technical University of Civil Engineering of Bucharest / Faculty of Hydrotechnics / Bucharest, Sector 2, 124 Lacul Tei Bvd., www.utcb.ro, Romania, Mobile No. +40723470737 the past decade has been an increased research activity in the application of reactor technology for the treatment of various types of industrial wastewaters, such as those from food processing, textile industry, paper and pulp industry. It was stated that high rate anaerobic systems represent a low cost and sustainable technology for industrial wastewaters treatment, because of its low construction, operation and maintenance cost, small land requirements, low excess sludge production and biogas generation, [2].

Food industries are one of the most important industries that need wastewater treatment plants. The constituents of food industry wastewaters are often difficult to predict due to the differences in chemical oxygen demand (COD) and $\mathrm{pH}$ in effluents from food products and the seasonal nature of food processing and post harvesting. Nevertheless, the researchers showed that wastewaters from the food industry are generally biodegradable and nontoxic, and have high concentrations of COD and suspended solid (SS), [3]. Companies in the food industry need large quantities of water for the production process and to clean raw materials, machinery, and equipment, thus disposal large quantities of water as a wastewater. Therefore, the wastewater should be treated and reused. This resource is helping to reduce the costs. Also, the integration of anaerobic and aerobic degradation has been used significantly in industrial and municipal wastewater treatment for many years, while previously most treatment of wastewaters has been carried out in conventional anaerobicaerobic treatment plants, in recent years, high rate anaerobicaerobic bioreactors have been increasingly employed for wastewaters with high chemical oxygen demand (COD), [4]. The integration of anaerobic and aerobic degradation pathways in a single bioreactor is capable of enhancing the overall degradation efficiency, [4]. The biological wastewater treatment process enables companies to recycle used water and thus reduce total consumption. Membrane bioreactor systems are used with biological treatment as an alternative to secondary processing, which offers many advantages over traditional activated sludge processes, such as good control of biological activity, excellent effluent quality, and good disinfection capability, higher of loading rates, smaller plant size, reduced sludge production, process flexibility towards influent changes, and improved nitrification, [3]. MBR technology has proven quite effective in removing organic and inorganic contaminants as well as microorganisms from wastewater, and has gained increasing popularity because the stricter environmental regulations and the increasing initiatives to reuse water in recent years, [5]. To date, MBR systems significant progress has been achieving in research and practical applications. In conjunction with this progress, the domain application of municipal wastewater treatment and some special areas in the industrial wastewater treatment sector has expanded. In cases where complex, high-strength industrial waste streams are treated and the settling and clarification problems are 
regularly encountered, MBR systems become an optimum option, [3]. This article deals with the industrial wastewater treatment from the food industry of meat processing factory located in Bucharest-Romania by anaerobic-aerobic processing using membrane bioreactor system, $\left(\right.$ ZeeWeed $^{\circledR}-10$ MBR).

\section{MEMBRANE BIOREACTOR SYSTEM}

ZeeWeed ${ }^{\circledR}$ membrane bioreactor systems combine proven ultrafiltration technology with biological treatment for municipal, commercial and industrial wastewater treatment and water reuse applications, [6]. ZeeWeed ${ }^{\circledR}-10(\mathrm{ZW}-10)$ is a unique outside-in hollow fiber module that operates under a low vacuum instead of high pressure, which means the overall energy costs are lower than traditional pressure driven systems. In addition, the low Trans-Membrane Pressure (TMP) means that the rate of fouling is lower than pressure driven processes. Since it is an outside-in hollow fiber, there is no risk of plugging of the flow channels with suspended solids, [7]. The ZW-10 membrane is manufactured by ZENON with an OCP chemistry. This chemistry produced a membrane with a pore size of $0.036 \mu \mathrm{m}$. The distinctive feature of the ZeeWeed ${ }^{\circledR}$ membrane is that it is immersed in the fluid that requires it to be treated. This means that the system occupies very small footprints as well as an important possibility to allow rehabilitation of existing plants by installing the membranes in existing clarifiers, bioreactors, and other tanks. The membrane is designed for chlorine oxidant tolerance up to $2000 \mathrm{ppm}$, which means that it can be utilized in disinfection systems, or easily cleaned with powerful oxidants.

\section{EXPERIMENTAL PROCESSES}

\section{A. Practical Method}

The wastewater provided by food industry factory of meat processing was used as a sample of industrial wastewater in this study. The anaerobic-aeration biodegradation of activated sludge was used in three phases. The first phase was conducted in 14/Nov./2017, and the second phase was conducted in 19/Nov./2017, while the third phase was conducted in 24/Nov./2017. The hydraulic retain times (HRTs) for these phases were selected to be 2, 4, 8, and 24 hours respectively with adding $\mathrm{NaOCl}$ solution in the bioreactor tank during the backwashing process. In these phases, a sample of 450 liters of industrial wastewater was collected and distributed to three tanks of 200 liters. 150 liters of industrial wastewater sample was pumped for each tank with 6 liters of activated sludge liquid at a concentration of $3.542 \mathrm{~g} / \mathrm{l}$ or $21.252 \mathrm{~g}$ of activated sludge concentration. The mixtures of wastewater and activated sludge were fermented for 5, 10, 15 days respectively, which a sample of water was taken, then the aerobic treatment process was started by pumping air through the air diffusers at a flow rate of 6 liters/min with HRTs 2, 4, 8, and 24 hours after that the mixed liquid was pumped from the anaerobic tank to the activated sludge tank in the pilot plant then the bioreactor treatment was carried out using MBR as shown in Figure 1.

This process is repeated in each tank. During the bioreactor treatment, $\mathrm{NaOCl}$ was pumped with the backwashing process at the flow rate of $8 \mathrm{~L} / \mathrm{min}$ to prevent the clogging of membranes. The treatment process and backwash process were programmed at time $600 \mathrm{sec}$, and 30 $\mathrm{sec}$ respectively by PLC automation. The aeration process in the bioreactor was performed by pumping the purified air from the base of the membrane at flow rate $50 \mathrm{~L} / \mathrm{min}$ to prevent the clogging of the membrane.

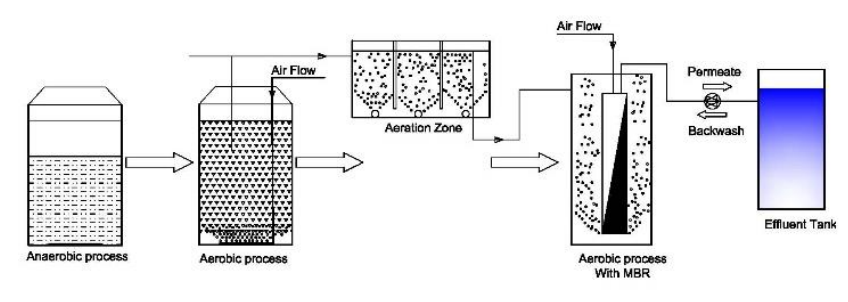

Fig. 1. Schematic diagram of the anaerobic-aerobic process used with MBR system.

\section{B. Water Quality Parameters and Sampling Tests}

The influent and effluents of the bioreactor system were tested for various of water quality parameters to examine its efficiency in wastewater treatment. These parameters are divided into two parts:

\section{$>\quad$ Physical tests}

$>\quad$ Biochemical tests

The physical tests were carried out on the site and consisted of temperature, dissolved oxygen and $\mathrm{pH}$, while the biochemical tests were conducted in the laboratory and consisted of mixed liquor suspended solids, total suspended solids, biochemical oxygen demand, chemical oxygen demand, and turbidity.

Twenty-eight of samples were collected to analyze physical and biochemical tests. The samples were taken from the storage tank as soon as reach to the laboratory, plastic tank (fermenting tank), activated sludge tank, and effluent tank. Regarding the first phase, a sample of influent from the anaerobic tank after 5 days of fermentation was taken as an effluent of anaerobic treatment, then eight samples from influent and effluent were taken at HRT 2, 4, 8, and 24 hours during bioreactor process. Raw wastewater sample was taken from the storage tank at reached to the laboratory in 09-Nov.-2017. For the second phase, a sample of anaerobic effluent was collected after 10 days of fermentation. While, eight samples of influent and effluent were collected at HRT $2,4,8$, and 24 hours during the bioreactor process. As the same sequence, the sample of anaerobic effluent was collected after 15 days of fermentation, then, eight samples of influent and effluent were collected at HRT 2, 4, 8, and 24 hours, during the bioreactor treatment. The constant periods of hydraulic retention time during aerobic biodegradation and filtration process with various fermentation period was selected to determine the $\mathrm{BOD}_{5}, \mathrm{COD}$, and TSS removal efficiencies, as well as determine the effect of the chemical compound represented by $\mathrm{NaOCl}$ solution on the treatment efficiency. The DO, $\mathrm{pH}$, and temperature were measured on-site before sampling.

\section{RESULTS AND DISCUSSIONS}

The collected samples were subjected to eight physical and biochemical tests. The biochemical tests were carried out in the chemical laboratory of UTCB and consisted of TSS, MLSS, $\mathrm{BOD}_{5}, \mathrm{COD}$, and turbidity, while the physical tests were carried out on the site and consisted of $\mathrm{DO}, \mathrm{pH}$, and temperature. The codes of influent samples were I1, I2, and I3 during phases PI, PII, and PIII respectively, while the codes of effluent were E1, E2, and E3 during the phases PI, 
PII, and PIII respectively. Analysis of these results is presented in the following subsections.

\section{A. Temperature}

The temperature of the wastewater samples during anaerobic biodegradation ranged between 18 to $19.3{ }^{\circ} \mathrm{C}$, see Figure 2, while for the aerobic degradation and bioreactor treatment ranged between 18.1 to $19.9{ }^{\circ} \mathrm{C}$. Table 1 shows summarizes maximum, minimum, and average of the temperature measurements for the three phases. For phase I, the variation of temperature ranged between 18.7 to $19.9{ }^{\circ} \mathrm{C}$ with gradually increased during biological and bioreactor treatment except at time 24 hours where it was decreased, as shown in Figure 3.

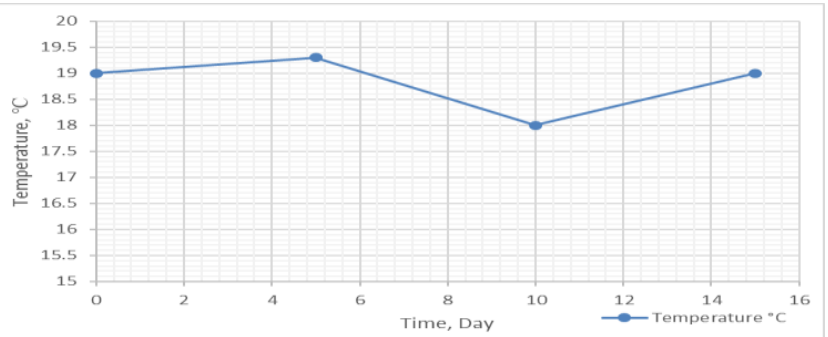

Fig. 2. Variation of the temperature during anaerobic biodegradation.

Table 1. Summary of the temperature level.

\begin{tabular}{|l|r|r|r|r|r|r|}
\cline { 2 - 7 } \multicolumn{1}{c|}{} & \multicolumn{6}{c|}{ Temperature, ${ }^{\circ} \mathbf{C}$} \\
\cline { 2 - 7 } \multicolumn{1}{c|}{} & \multicolumn{2}{|c|}{ PI } & \multicolumn{1}{c|}{ PII } & \multicolumn{2}{c|}{ PIII } \\
\cline { 2 - 7 } \multicolumn{1}{c|}{} & I1 & E1 & \multicolumn{1}{|c|}{ |2 } & \multicolumn{1}{c|}{ E2 } & I3 & E3 \\
\hline Avg. & 19.2 & 19.5 & 18.9 & 19.2 & 18.8 & 19.2 \\
\hline Max. & 19.7 & 19.9 & 19.1 & 19.4 & 19.2 & 19.5 \\
\hline Min. & 18.7 & 19 & 18.4 & 19 & 18.1 & 18.4 \\
\hline
\end{tabular}

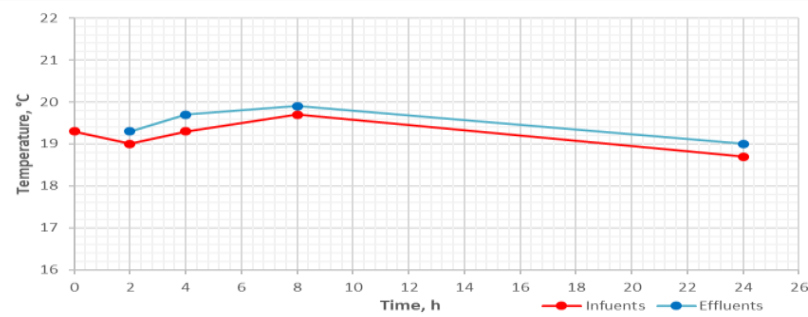

Fig. 3. Variations of the temperature during PI.

A similar variation was noticed for the phase II, where the temperature varied between 18.4 to $19.4^{\circ} \mathrm{C}$ with gradual increasing during the biological and bioreactor treatment as shown in Figure 4. While on the phase III, the gradually increase of temperature was observed during the first 4 hours of bioreactor process then it shown a gradually decrease up to $18.1^{\circ} \mathrm{C}$ after 24 hours of bioreactor process as shown in Figure 5, in general the variation of temperature ranged between 18.1 to $19.5^{\circ} \mathrm{C}$ in this phase.

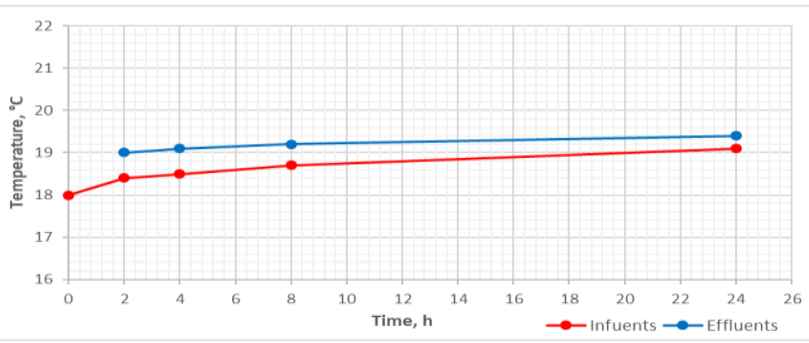

Fig. 4. Variations of the temperature during PII.

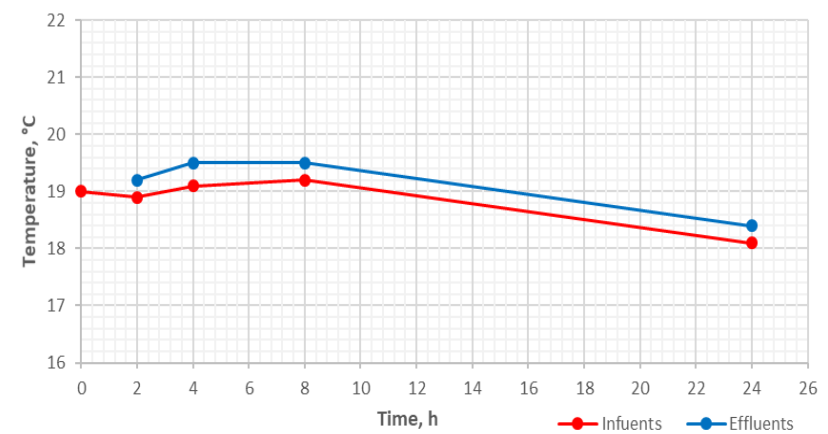

Fig. 5. Variations of the temperature during the PIII.

Generally, the temperature of effluent was higher than on the influent for all experimental trials carried out, this may due to the friction between the surface area of the membrane and the liquid during the filtration process, moreover the biochemical processes of microorganisms in the bioreactor. The temperature ranges were not in well biodegradable conditions, because the temperature range of 30 to $35^{\circ} \mathrm{C}$ is the best range for growth of microorganisms, [8].

\section{B. Dissolved Oxygen}

The air flow was pumped into the plastic tank (fermentation tank) and activated sludge tank at a flow rate of $6 \mathrm{~L} / \mathrm{min}$, while in the bioreactor tank was $50 \mathrm{~L} / \mathrm{min}$ for all phases conducted. The dissolved oxygen concentrations, DO at all phases were summarized in Table 2 as a maximum, minimum, and average of DO. The DO concentrations during anaerobic biodegradation were to be zero for all phases, whereas for aerobic biodegradation, a decreased of the DO concentration was observed in influents during the biological treatment of activated sludge, where varied between 2.16 to $3.05 \mathrm{mg} / \mathrm{L}$ in PI, as well as for the effluent where the DO varied between 5.37 to $7.39 \mathrm{mg} / \mathrm{L}$ in the PI, as shown in Figure 6. In the PII, the DO concentrations for influent varied between 3.00 to $4.28 \mathrm{mg} / \mathrm{L}$ with gradual decreasing during biological treatment and the effluent varied between 8.63 to $8.85 \mathrm{mg} / \mathrm{L}$, as shown in Figure 7. Thus, for the PIII, a gradual decreased of the DO concentration in the influents was observed with aeration time where the concentration of DO varied between 4.95 to $6.84 \mathrm{mg} / \mathrm{L}$, as well as in effluents, where the concentration of DO varied between 8.85 to 9.03 $\mathrm{mg} / \mathrm{L}$ during bioreactor treatment, as shown in Figure 8.

Table 2. Summary of the DO concentrations.

\begin{tabular}{|l|r|r|r|r|r|r|}
\cline { 2 - 8 } \multicolumn{1}{c|}{} & \multicolumn{6}{c|}{ Dissolved Oxygen, $\boldsymbol{m g} / \mathbf{L}$} \\
\cline { 2 - 8 } \multicolumn{1}{c|}{} & \multicolumn{2}{c|}{ PI } & \multicolumn{2}{c|}{ PII } & \multicolumn{2}{c|}{ PIII } \\
\cline { 2 - 8 } & I1 & E1 & \multicolumn{1}{c|}{ I2 } & \multicolumn{1}{c|}{ E2 } & \multicolumn{1}{c|}{ I3 } & \multicolumn{1}{c|}{ E3 } \\
\hline Avg. & 2.4 & 6.3 & 3.9 & 8.7 & 5.9 & 8.9 \\
\hline Max. & 3.1 & 7.4 & 4.3 & 8.9 & 6.8 & 9 \\
\hline Min. & 2.2 & 5.4 & 3 & 8.6 & 5 & 8.9 \\
\hline
\end{tabular}

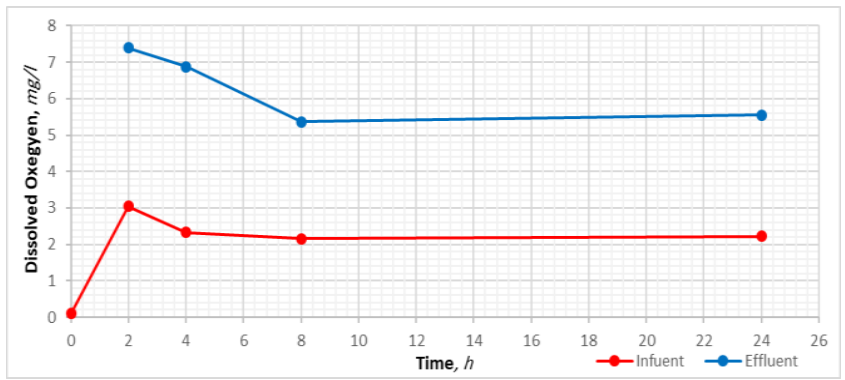

Fig. 6. Variations of the DO concentration in the PI. 


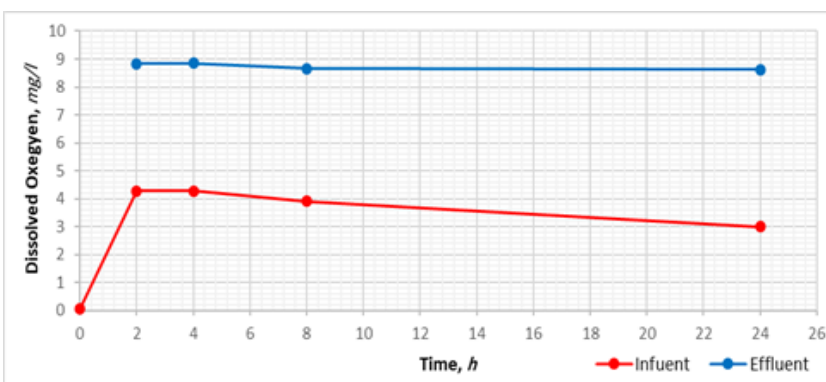

Fig. 7. Variations of the DO concentration during the PII.

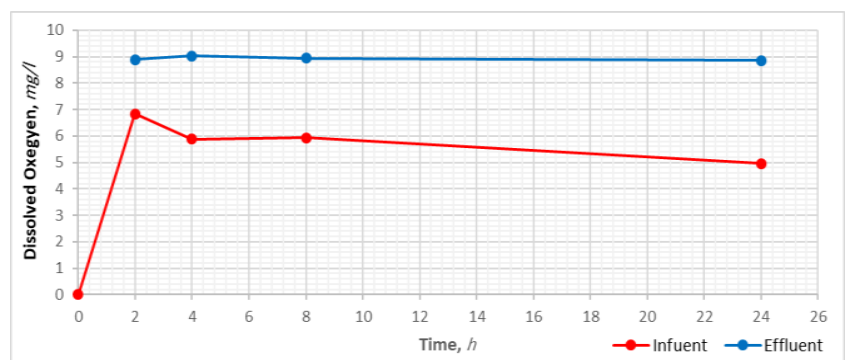

Fig. 8. Variations of the DO concentration during the PIII.

The pumped air to the bioreactor was measured in different points and found to be more than $5 \mathrm{mg} / \mathrm{L}$, continuously during all experimental trials runs. The total requirements of DO were $5 \mathrm{mg} / \mathrm{L}$ for the biochemical processes to obtain a better growth of microorganisms and organic biodegradation, [9].

\section{PH value}

The variation of the $\mathrm{pH}$ values in PI, PII, and PIII tests are shown in Figures 9, 10, and 11 respectively. Table 3 summarizes the maximum, minimum, and average values of $\mathrm{pH}$ for these tests. During the fermentation, the $\mathrm{pH}$ values were lower than 7 for all phases and they slightly decreased with the time of fermentation as shown in Figure 12. While, during the aerobic process, it was observed that all $\mathrm{pH}$ values were higher than 7 with a gradual increased during the treatment. The $\mathrm{pH}$ values of the effluent during the experiments were higher than that of the influent, because of $\mathrm{NaOCl}$ effect in the bioreactor and indicate an alkaline solution.

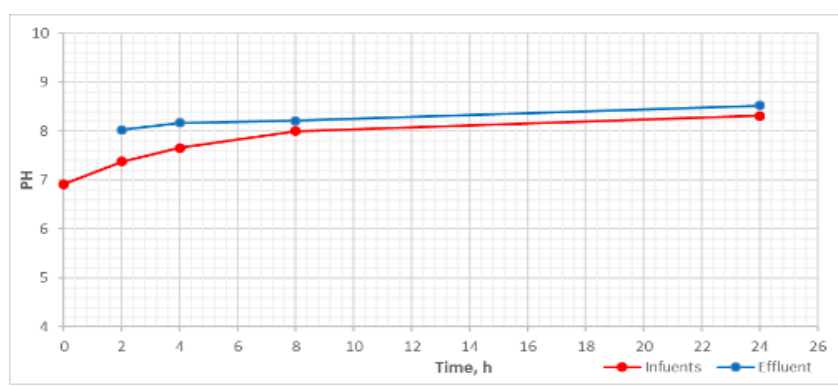

Fig. 9. Variations of $\mathrm{pH}$ value during the PI.

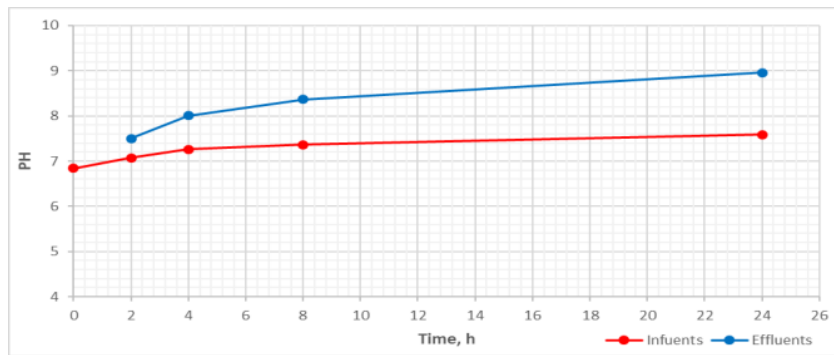

Fig. 10. Variations of $\mathrm{pH}$ value during the PII.

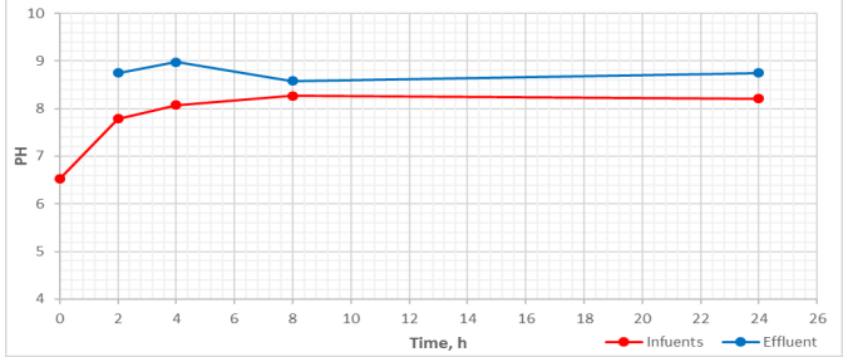

Fig. 11. Variations of $\mathrm{pH}$ value during the PIII.

Table 3. Summary of the $p H$ values.

\begin{tabular}{|c|c|c|c|c|c|c|}
\hline & \multicolumn{6}{|c|}{ pH } \\
\hline & \multicolumn{2}{|c|}{ PI } & \multicolumn{2}{|c|}{ PII } & \multicolumn{2}{|c|}{ PIII } \\
\hline & I1 & E1 & I2 & E2 & I3 & E3 \\
\hline Avg. & 7.84 & 8.23 & 8.03 & 8.51 & 8.09 & 8.77 \\
\hline Max. & 8.31 & 8.52 & 8.13 & 8.65 & 8.27 & 8.98 \\
\hline Min. & 7.38 & 8.03 & 7.76 & 8.27 & 7.79 & 8.58 \\
\hline
\end{tabular}

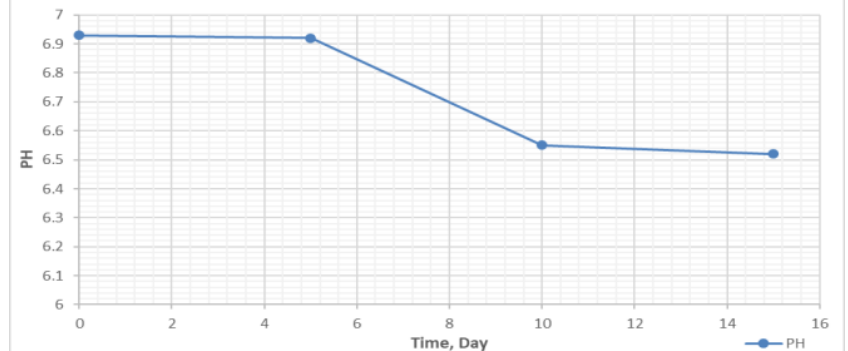

Fig. 12. Variation of $\mathrm{pH}$ value during anaerobic biodegradation.

\section{Turbidity}

The turbidity concentration of wastewater for anaerobic degradation process during PI, PII, and PIII tests was 25.81, 30.03, and 41.61 NTU respectively, see Figure 13. While the tested values of the turbidity during bioreactor process for all phases were summarized in table 4 as an average, maximum, and minimum values of influents and effluents. Figures 14, 15 , and 16 shows the concentration of turbidity in influents and effluents for PI, PII, and PIII tests. It is noteworthy that the turbidity concentration of raw wastewater was 205 NTU.

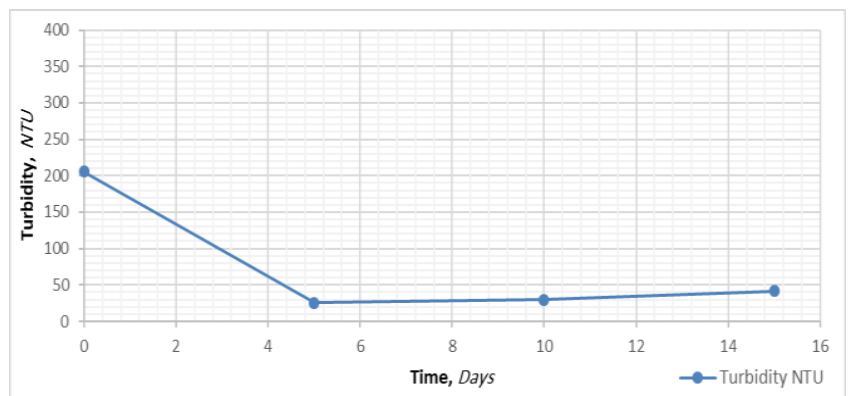

Fig. 13. Variation of turbidity during anaerobic biodegradation.

Table 4. Summary of turbidity concentrations.

\begin{tabular}{|l|r|r|r|r|r|r|}
\cline { 2 - 8 } & \multicolumn{6}{c|}{ Turbidity, NTU } \\
\cline { 2 - 8 } & \multicolumn{2}{|c|}{ PI } & \multicolumn{2}{c|}{ PII } & \multicolumn{2}{c|}{ PIII } \\
\cline { 2 - 8 } & \multicolumn{1}{|c|}{ I1 } & E1 & I2 & E2 & \multicolumn{1}{c|}{ I3 } & E3 \\
\hline Avg. & 45.7 & 0.7 & 85.85 & 1 & 266 & 1.8 \\
\hline Max. & 84.9 & 1 & 146 & 1.2 & 388.8 & 2.2 \\
\hline Min. & 25.4 & 0.2 & 52.61 & 0.6 & 191.2 & 1.8 \\
\hline
\end{tabular}




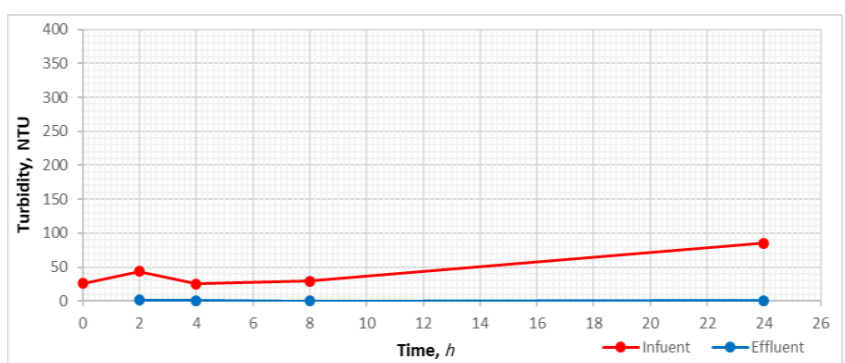

Fig. 14. Variations of turbidity concentration in PI tests.

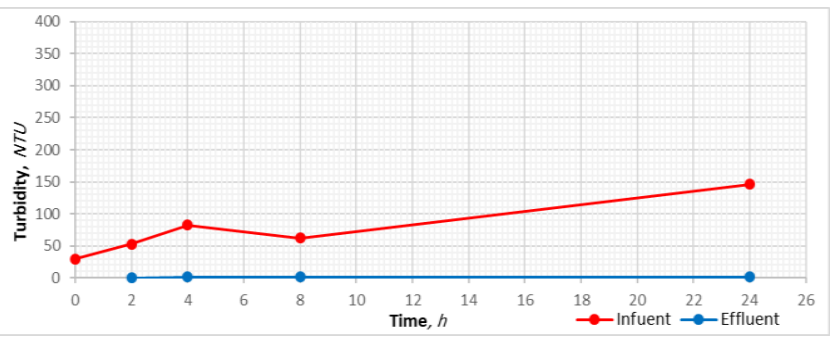

Fig. 15. Variations of turbidity concentration in PII tests.

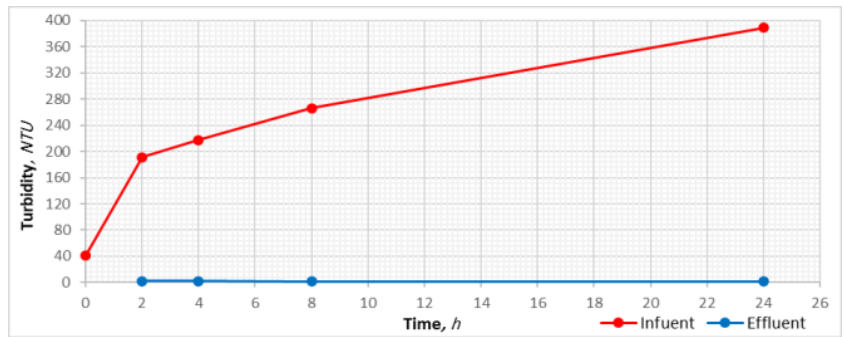

Fig. 16. Variations of turbidity concentration in PIII tests.

The percentage of turbidity removal during the anaerobic process was $87.45 \%, 85.40 \%$, and $79.70 \%$ respectively. While for bioreactor process, the membrane filter showed an excellent turbidity removal, where the removal of turbidity varied between $99.50 \%$ and $99.88 \%$ for PI tests, and $99.40 \%$ and $99.73 \%$ for PII tests, and $98.60 \%$ and $99.88 \%$ for PIII tests.

In general, all the turbidity of effluents during runs for all tests were much less than that of the influents, this indicates that the membrane filter was very efficient in retaining solids.

\section{E. Suspended Solids}

The tested values of the mixed liquor suspended solids and total suspended solids during anaerobic biodegradation process are shown in Figure 17, where a gradual decrease can be observed with increased fermentation time. The TSS value of raw wastewater was $522 \mathrm{mg} / \mathrm{L}$, while the TSS value of the wastewater fermented during the anaerobic process was 248 , 236, and $178 \mathrm{mg} / \mathrm{L}$ respectively, also the MLSS value was 5966,5780 , and $4446 \mathrm{mg} / \mathrm{L}$ respectively.

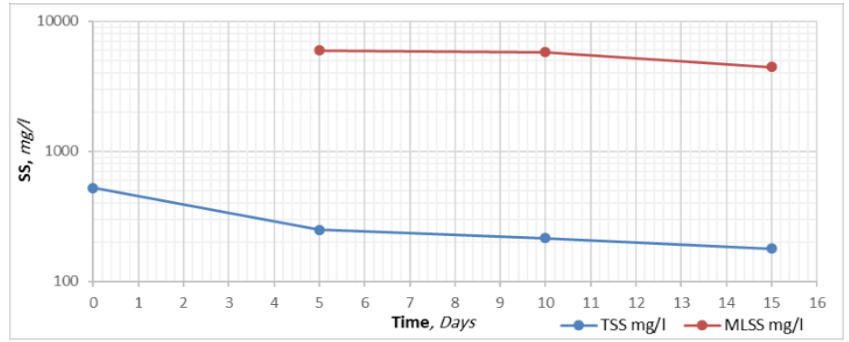

Fig. 17. Variation of TSS and MLSS concentrations during anaerobic biodegradation.
The percentage of TSS removal during the anaerobic process was $52.5 \%, 59.0 \%$, and $65.9 \%$ respectively. During the bioreactor process, the tests of MLSS and TSS showed a gradual decreasing with aeration time in each of PI, PII and PIII as shown in Figures 18, 19, and 20 respectively. The average, maximum, and minimum values of MLSS concentration for influents and TSS concentration for effluents in these phases are summarized in table 5 .

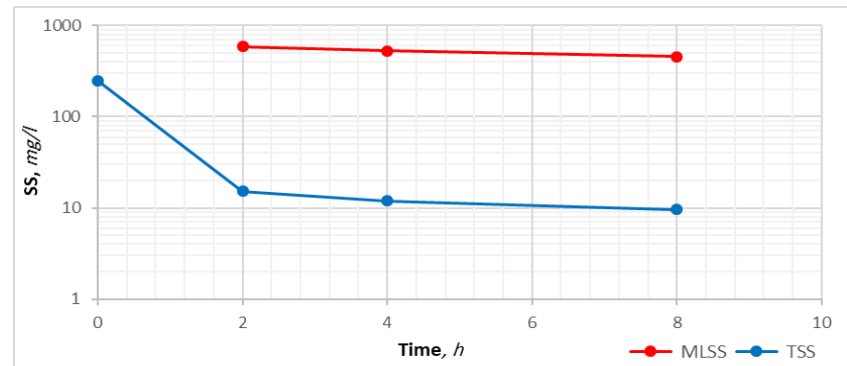

Fig. 18. Variations of MLSS and TSS concentration in PI tests.

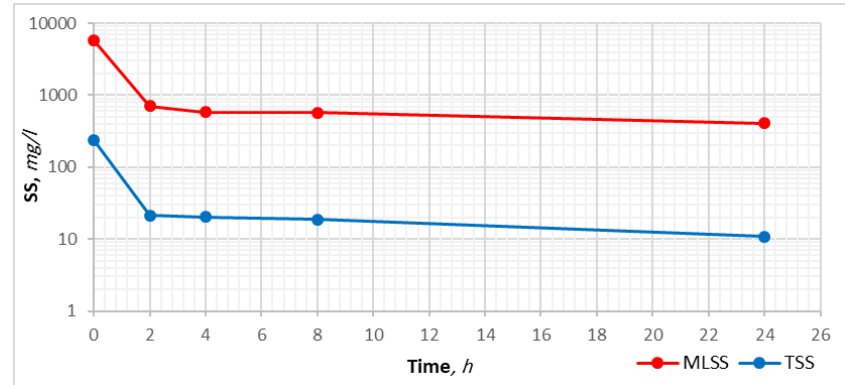

Fig. 19. Variations of MLSS and TSS concentration in PII tests.

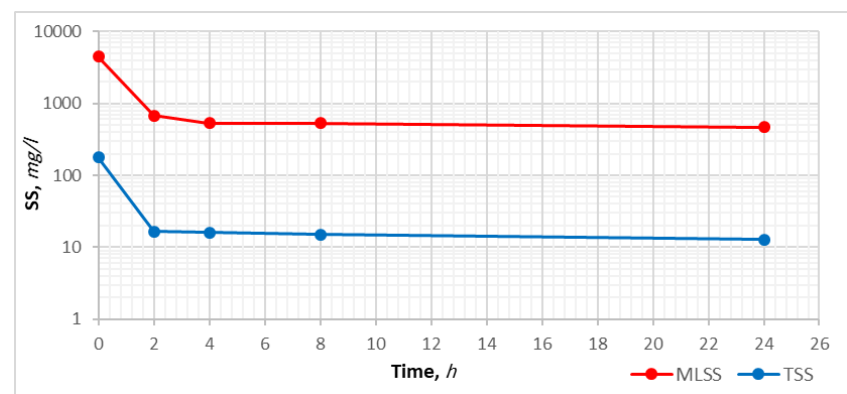

Fig. 20. Variations of MLSS and TSS concentration in PIII tests.

Table5. Summary of the MLSS and TSS concentrations.

\begin{tabular}{|c|c|c|c|c|c|c|}
\cline { 2 - 7 } \multicolumn{1}{c|}{} & \multicolumn{6}{c|}{ MLSS \& TSS, mg/L } \\
\cline { 2 - 7 } \multicolumn{1}{c|}{} & \multicolumn{2}{|c|}{ PI } & \multicolumn{2}{c|}{ PII } & \multicolumn{2}{c|}{ PIII } \\
\cline { 2 - 7 } \multicolumn{1}{c|}{ I1 } & E1 & I2 & E2 & I3 & E3 \\
\hline Max. & 491 & 11.4 & 567.5 & 17.85 & 553 & 15.1 \\
\hline Min. & 392 & 15.2 & 706 & 21.4 & 682 & 16.6 \\
\hline
\end{tabular}

Total suspended solids are greatly related to the turbidity. Overall, membrane filters showed excellent removal of TSS in all experimental trials performed.

The TSS removal efficiency during all tests performed in PI varied between $97.09 \%$ and $98.31 \%$, while during PII, the removal efficiency varied between $95.9 \%$ and $97.93 \%$, also, the removal efficiency of TSS during PIII varied between $96.82 \%$ and $97.55 \%$. These results indicate an excellent solids separation achieved by the ultrafiltration (UF) membrane through removal of TSS, which achieved a 
removal efficiency greater than $95 \%$ for all experimental trials conducted, resulting to produce low concentration of TSS in permeate (below $22 \mathrm{mg} / \mathrm{L}$ ), that indicates a high efficiency of the membrane to separate the retentate and remove the suspended solids concentrations.

\section{F. Chemical Oxygen Demand}

The COD value of raw wastewater was $2457.6 \mathrm{mg} / \mathrm{L}$, then a significant reduction of COD concentration has been observed after 5 days of anaerobic biodegradation process where reach to $1267.2 \mathrm{mg} / \mathrm{L}$, then a gradual increased with time of fermentation has been observed as shown in Figure 21. The percentage of COD removal during anaerobic biodegradation was $48.4 \%, 47.3 \%$, and $19.5 \%$ respectively. For the bioreactor process, the average, maximum, and minimum COD values of influents and effluents for PI, PII, and PIII are summarized in Table 6.

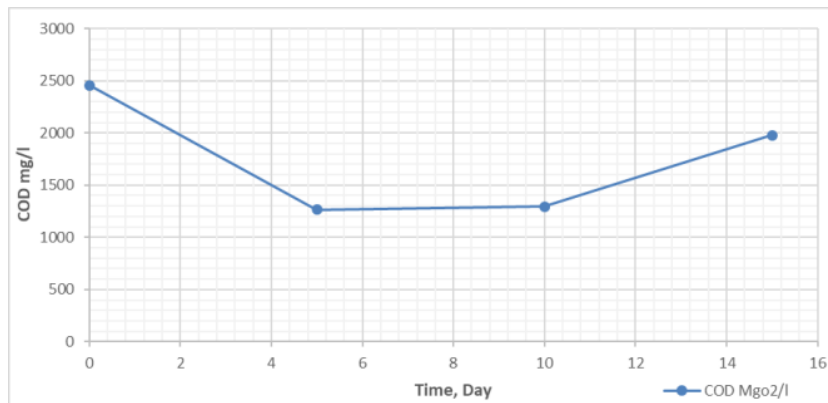

Fig. 21. Variation of COD concentrations during anaerobic biodegradation.

Table 6. Summary of the COD concentrations.

\begin{tabular}{|c|c|c|c|c|c|c|}
\cline { 2 - 8 } & \multicolumn{6}{c|}{ COD, $\boldsymbol{m g} / \mathbf{L}$} \\
\cline { 2 - 8 } & \multicolumn{2}{|c|}{ PI } & \multicolumn{2}{c|}{ PII } & \multicolumn{2}{c|}{ PIII } \\
\cline { 2 - 8 } & I1 & E1 & I2 & E2 & I3 & E3 \\
\hline Avg. & 1104 & 552 & 1279 & 624 & 1867 & 924 \\
\hline Max. & 1306 & 749 & 1555 & 854 & 2074 & 1114 \\
\hline Min. & 653 & 134 & 720 & 202 & 1382 & 595 \\
\hline
\end{tabular}

As for aerobic biodegradation and bioreactor treatment, the COD tests showed a gradual decrease in the COD value that was observed in all phases, as shown in Figures. 22, 23 and 24 , respectively. It was also observed that the minimum COD concentration during aerobic biodegradation at all phases was in PI, where reaching $653 \mathrm{mg} / \mathrm{L}$ for influent and $134 \mathrm{mg} / \mathrm{L}$ for effluent at fourth run (HRT=24h).

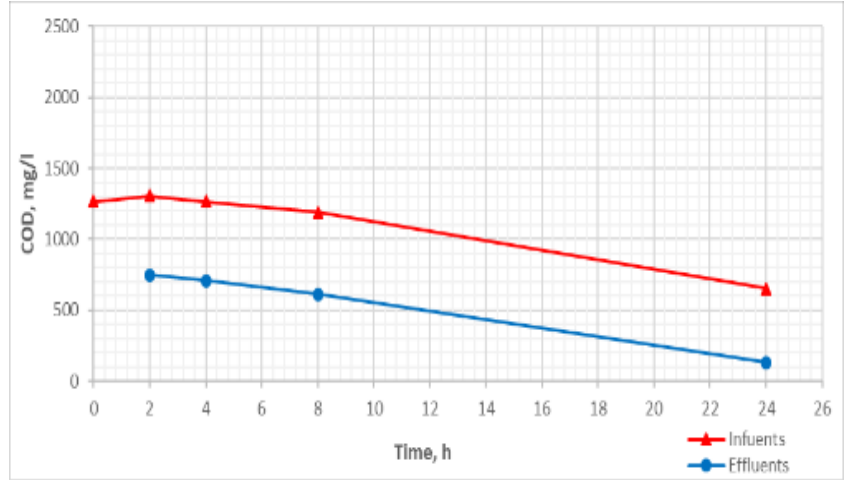

Fig. 22. Variations of COD concentration in PI tests.

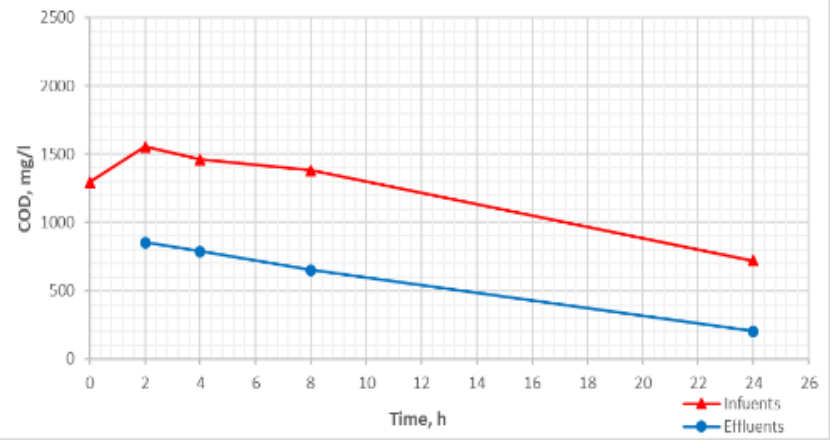

Fig. 23. Variations of COD concentration in PII tests.

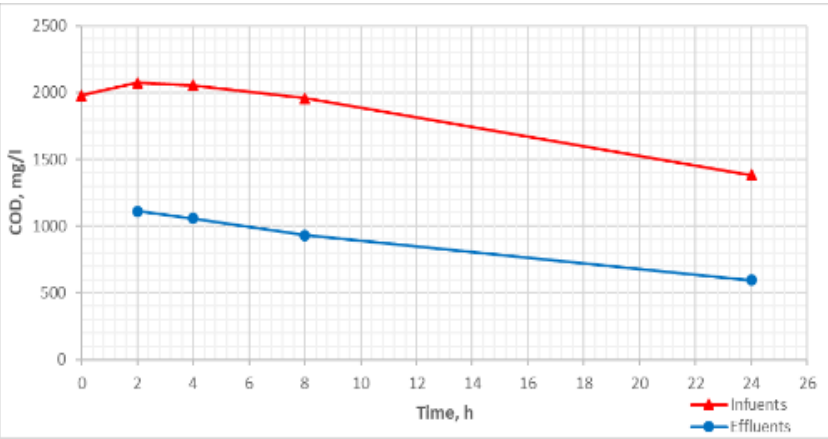

Fig. 24. Variations of COD concentration in PIII tests.

The COD removal efficiency during all tests performed in PI varied between $69.5 \%$ and $94.5 \%$, while the removal efficiency of COD during all tests performed in PII varied between $59 \%$ and $79.3 \%$. Also, the removal efficiency of COD during PIII varied between $54.7 \%$ and $75.8 \%$. Thus, the best removal of COD was in the fourth run of the first phase PI at HRT $24 \mathrm{~h}$.

\section{G. Biochemical Oxygen Demand}

The $\mathrm{BOD}_{5}$ value of raw wastewater was $1442 \mathrm{mg} / \mathrm{L}$. The $\mathrm{BOD}_{5}$ value of raw wastewater was $1442 \mathrm{mg} / \mathrm{L}$. During anaerobic biodegradation, a reduction of $\mathrm{BOD}_{5}$ concentration was observed during anaerobic process where was 1109, 963, and $847 \mathrm{mg} / \mathrm{L}$, respectively, as shown in Figure 25. The removal efficiency of $\mathrm{BOD}_{5}$ during anaerobic biodegradation was $23.09 \%, 33.22 \%$ and $41.26 \%$, respectively. During the aerobic biodegradation and bioreactor treatment, the $\mathrm{BOD}_{5}$ tests show a gradual decrease of the $\mathrm{BOD}_{5}$ concentration with the time of aeration for all phases, as shown in Figures. 26, 27 and 28 respectively. The average, maximum, and minimum $\mathrm{BOD}_{5}$ values of influents and effluents for PI, PII, and PIII are summarized in Table 7.

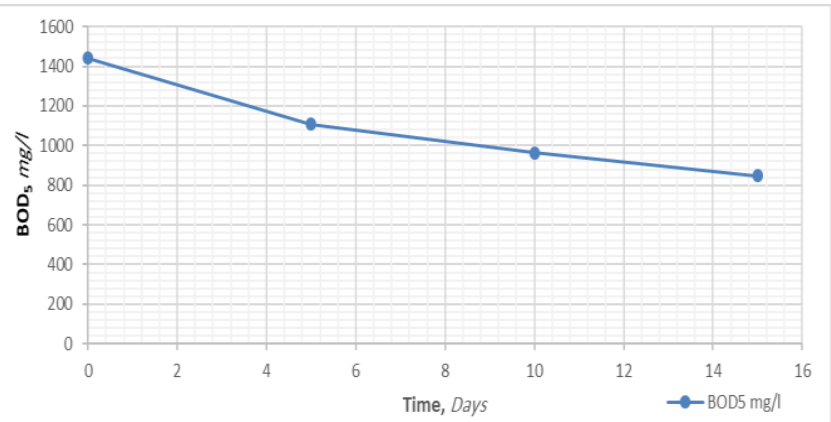

Fig. 25. Variation of $\mathrm{BOD}_{5}$ concentrations during anaerobic biodegradation. 
Table 7. Summary of the $\mathrm{BOD}_{5}$ concentrations.

\begin{tabular}{|l|r|r|r|r|r|r|}
\cline { 2 - 8 } \multicolumn{1}{c|}{} & \multicolumn{6}{c|}{ BOD $_{\mathbf{5}}, \mathbf{~ m g / L}$} \\
\cline { 2 - 7 } \multicolumn{1}{c|}{} & \multicolumn{2}{|c|}{ PI } & \multicolumn{1}{c|}{ PII } & \multicolumn{1}{c|}{ PIII } \\
\cline { 2 - 7 } & I1 & E1 & \multicolumn{1}{c|}{ I2 } & \multicolumn{1}{c|}{ E2 } & \multicolumn{1}{c|}{ I3 } & E3 \\
\hline Avg. & 755.5 & 76.5 & 872 & 175.5 & 780 & 437 \\
\hline Max. & 918 & 98 & 936 & 254 & 830 & 518 \\
\hline Min. & 494 & 64 & 711 & 90 & 706 & 387 \\
\hline
\end{tabular}

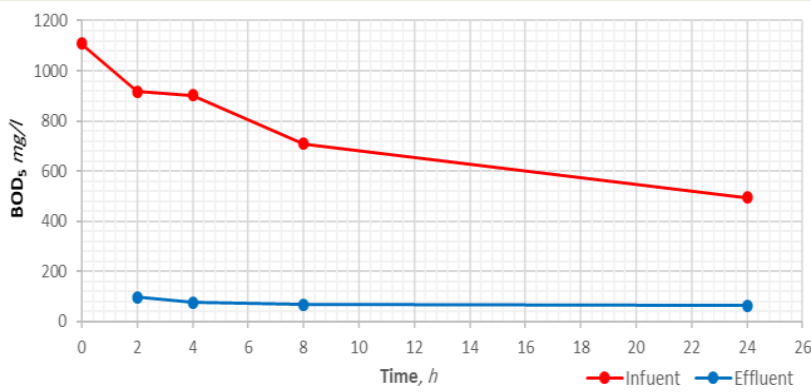

Fig. 26. Variations of $\mathrm{BOD}_{5}$ concentration in PI tests.

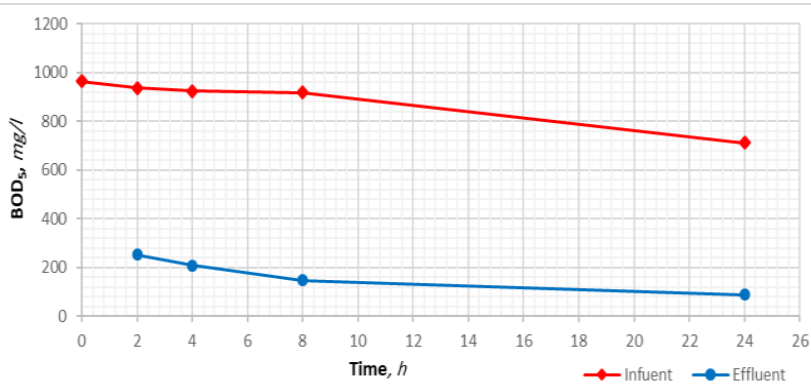

Fig. 27. Variations of $\mathrm{BOD}_{5}$ concentration in PII tests.

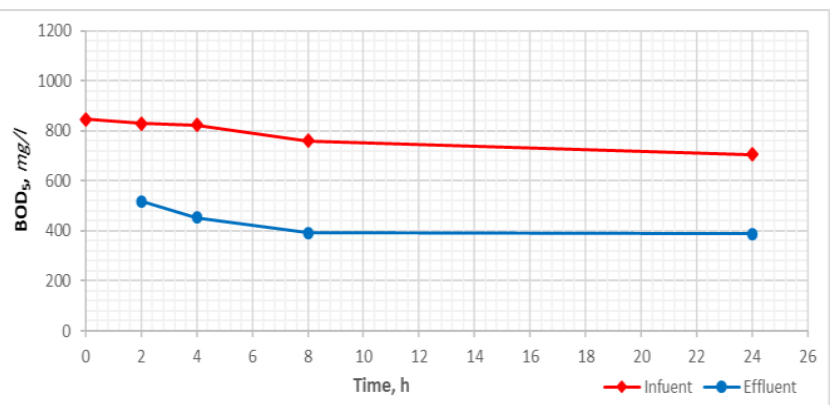

Fig. 28. Variations of $\mathrm{BOD}_{5}$ concentration in PIII tests.

The minimum $\mathrm{BOD}_{5}$ concentration during aerobic biodegradation for all phases was found in PII, at a value of $311 \mathrm{mg} / \mathrm{L}$, while the minimum $\mathrm{BOD}_{5}$ concentration during bioreactor process for all phases was found in PI, at a level of $64 \mathrm{mg} / \mathrm{L}$.

The $\mathrm{BOD}_{5}$ removal efficiency during all tests performed in PI varied between $93.2 \%$ and $95.56 \%$, while the removal efficiency of $\mathrm{BOD}_{5}$ during all tests performed in PII varied between $89.32 \%$ and $93.76 \%$. Also, the removal efficiency of $\mathrm{BOD}_{5}$ during PIII varied between $64.08 \%$ and $73.16 \%$. Thus, the best removal of $\mathrm{BOD}_{5}$ was in the fourth run of the first phase PI at HRT $24 \mathrm{~h}$ where was $95.56 \%$.

\section{SUMMERY AND CONCLUSION}

Wastewaters with high organic carbon concentrations $(2,457 \mathrm{mg} \mathrm{COD} / \mathrm{L})$ and $\left(1442 \mathrm{mg} \mathrm{BOD}_{5} / \mathrm{L}\right)$ can be treated in the biological biodegradation process with the bioreactor process technology. Three phases of anaerobic-aerobic biodegradation process with bioreactor by using MBR system produced by Zenon-General Electric Company with a membrane module ZW-10 were carried out in this study. The results obtained can be summarized as follows:

1. The $\mathrm{pH}$ value was gradually decreasing with the fermentation time during anaerobic pre-treatment process, where varied from 6.92 to 6.52 . That indicates an acidic media. During the aerobic process, it was observed that all $\mathrm{pH}$ values were higher than 7 with a gradual increase during the aeration period in all phases. The reason for this increase is the disintegration and oxidation of the organic matter during the aeration process, which leads to the formation of $\mathrm{CO}_{2}$. Some part of the $\mathrm{CO}_{2}$ released as a gas from the aeration tank, that resulting in a decreasing of acidity in the water thus increasing the $\mathrm{pH}$ value. Also, the $\mathrm{pH}$ values of the Effluent during the bioreactor process were higher than that of the influent, may because of $\mathrm{NaOCl}$ effect in the bioreactor where indicate an alkaline solution.

2. The membrane filter showed an excellent turbidity removal during the bioreactor process, where the turbidity removal in the PI tests performed varied between $99.50 \%$ and $99.88 \%$. While in the PII tests the turbidity, removal varied between $99.40 \%$ and $99.73 \%$, and so in the PIII, where varied between $99.60 \%$ and $99.88 \%$, thus indicates that the membranes filter was very efficient in retaining solids.

3. Regarding the suspended solids, the TSS of raw wastewater was $522 \mathrm{mg} / \mathrm{L}$, and a gradual decreased has been observed of TSS concentration with fermentation time during anaerobic pre-treatment process, where varied from 248 to $178 \mathrm{mg} / \mathrm{L}$. The percentage of TSS removal during the anaerobic process ranged from $52.5 \%$ and $60.9 \%$. During the bioreactor process, the membrane filters achieved excellent removal of TSS for all experimental trials carried out during PI, PII, and PIII phases. They were observed that the minimum concentration of TSS at HRT $24 \mathrm{~h}$ in all phases with $8.8,10.8$ and $12.8 \mathrm{mg} / \mathrm{L}$, respectively. The highest removal efficiency in the first phase PI (i.e. after 5 days of anaerobic treatment) was achieved, by $98.31 \%$ at HRT $24 \mathrm{~h}$.

4. In terms of the Chemical Oxygen Demand, the raw wastewater had a high concentration of COD, (2457.6 $\mathrm{mgCOD} / \mathrm{L}$ ), during the anaerobic pre-treatment process, a significant reduction of COD was observed in the first phase PI, then gradually increasing into the phases "PII" and "PIII" respectively. The minimum concentration of COD during anaerobic degradation was in PI, where it was $1267 \mathrm{mg} / \mathrm{L}$, thus achieved the maximum removal efficiency, where reached $48.4 \%$. During the bioreactor process, a gradual decreasing of COD concentration with the aeration time had been observed during the bioreactor process for all phases and the minimum concentration of COD obtained was $134.4 \mathrm{mg} / \mathrm{L}$ in the PI (after 24 hours of aeration), thus achieved the highest removal efficiency where it was $94.53 \%$.

5. With regard to Biochemical Oxygen Demand, also the raw wastewater had a high concentration of $\mathrm{BOD}_{5}$, (1440 mg $\left.\mathrm{BOD}_{5} / \mathrm{L}\right)$, during anaerobic pre-treatment 
process, a significant reduction of $\mathrm{BOD}_{5}$ was observed in the first phase PI, then the decline continued gradually in the second phase "PII", while in the "PIII" there was an increase in the concentration of $\mathrm{BOD}_{5}$, this indicates a decrease in the number of activated microorganisms. The minimum concentration of $\mathrm{BOD}_{5}$ during anaerobic biodegradation was in PII, where it was $763 \mathrm{mg} / \mathrm{L}$, thus achieved a maximum removal efficiency, where reached $47.4 \%$. A significant decline of $\mathrm{BOD}_{5}$ was observed in PI during the bioreactor processing, while, the $\mathrm{BOD}_{5}$ concentrations of the effluents had increased in PII and PIII respectively. Also, a gradual decreasing of the effluent of $\mathrm{BOD}_{5}$ concentration with the aeration time had been observed during the bioreactor process for all phases and the minimum concentration of BOD5 obtained was $64 \mathrm{mg} / \mathrm{L}$ in the PI (after 24 hours of aeration), thus achieving the highest removal efficiency where it was $95.56 \%$.

6. The results showed that the first phase PI of the experimental trials in this study at HRT of $24 \mathrm{~h}$, considered as the best phase for treatment of industrial wastewater effluent of meat processing, which provided the highest removal efficiency for total suspended solids, biochemical oxygen demand, and chemical oxygen demand.

\section{REFERENCES}

[1] Nykova N., Muller T. G., Gyllenberg M., Timmer J., "Quantitative analyses of anaerobic wastewater treatment processes: identifiability and parameter estimation.," Biotechnology and Bioengineering, vol. 78, no. 1, pp. 89-103, 2002.

[2] B. Mrowiec, J. Suschka, "Anaerobic wastewater treatment process," University of Bielsko-Biala, Willowa 2 Street, Bielsko-Biala 43-309, Poland, 2009.

[3] Hongjun Lin , Weijue Gao, Fangang Meng, Bao-Qiang Liao, Kam-Tin Leung, Leihong Zhao, Jianrong Chen and Huachang Hong, "Membrane Bioreactors for Industrial Wastewater Treatment: A Critical Review," Critical Reviews in Environmental Science and Technology, Copyright () Taylor \& Francis Group, LLC, vol. 42, no. 7, p. 677-740, 2012.

[4] Yi Jing Chan, Mei Fong Chong*, Chung Lim Law, D.G. Hassell, "A review on anaerobic-aerobic treatment of industrial and municipal wastewater," Chemical Engineering Journal, vol. 155, no. 1-2, p. 1-18, 2009.

[5] K.Ozan, C.Acikgoz, "Treatment of domestic wastewater by membrane bioreactor system (MBR)," Journal of Engineering Research and Applied Science, vol. 5, no. 2, pp. 494-498, 2016.

[6] Process overview ZeeWeed® MBR, "wateronline," 2808 2005. [Online]. Available:

https://www.wateronline.com/doc/process-overview-zeeweed-mbr-0001.

[7] Appendix B Zenon Design and Pilot Report, , "Maple Leaf Brandon - Pilot Report," $\quad 06 \quad 01 \quad 2003 . \quad$ [Online]. Available: http://www.gov.mb.ca/sd/eal/registries/brandonwastewater/eia/append-b.pdf.

[8] J. Coppen, "advanced wastewater treatment systems - ZetaTalk," 04102004. [Online]. Available: http://eprints.usq.edu.au/id/eprint/17. [Accessed 0207 2013].

[9] F. R. Spellman, Handbook of water and wastewater treatment plant operation, 2003, CRC press LLC, Boca Raton London New York Washington, D.C: CRC Press Company, 2003.

Al-Saadi Anmar Joudah, I am a doctoral student at the Technical University of Civil Engineering Bucharest, Faculty of Hydrotechnics, specialization, Water Treatment Engineering, My Research Project on Industrial Wastewater Treatment in Romania, this article is one of the results obtained during the study.

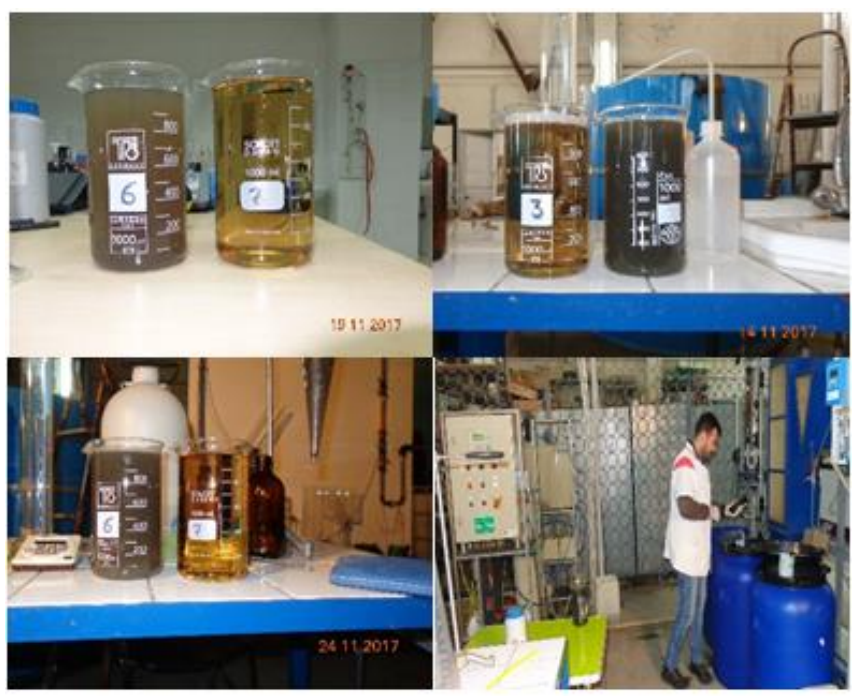

